\title{
Assessment of the resource efficiency of the gas industry in the context of sustainable development
}

\author{
Larisa Vazhenina $^{1, *}$, and Vladimir Cibulsky ${ }^{2}$ \\ ${ }^{1}$ Tyumen Industrial University, 625001 Tyumen, Russia \\ ${ }^{2}$ Tyumen Scientific Center SB RAS, 625026 Tyumen, Russia
}

\begin{abstract}
In the study, within the framework of the concept of sustainable development, a methodology for a comprehensive assessment of resource efficiency based on an integral indicator is proposed as a predictive tool. The resource-efficient forecast is carried out through the implementation of the gas industry companies ' own development strategies. This set of indicators in assessing resource efficiency allows you to identify the segments of gas production, processing and transportation and assess their contribution to the overall resource efficiency of the gas industry. To identify the impact of resource-efficient development of each segment of the industry on the socioeconomic system of the territory. Identify areas and develop measures to improve the resource efficiency of gas companies and the economic security of the country as a whole.
\end{abstract}

\section{Introduction}

Efforts are also continuing to further expand the concept of fuel and energy efficiency, in particular the use of multi-purpose (multi-criteria) approaches that reflect not only economic, but also social requirements of society for energy (for example, nuclear) [1].

The literature describes a large number of systems that support management decisions in the energy and economy - from systems whose scope is limited to the management of individual energy carriers, to complex systems that consider the energy sector as an integral part of the economy (Borges \& Antunes, 2003; SCANER, 2011) [2-4]. Existing systems for supporting management decisions in the energy sector are characterized by a wide variety of decision-making models, which are reviewed, discussed, and compared in articles (Psarras, Capros \& Samouilidis, 1990; Greening \& Bernow, 2004; Becalli, Cellura \& Mistetta, 2003). The paper (Capros et al., 1990) examines theoretical and empirical problems that arise when creating systems of "energy-economy" models used for short-and medium-term forecasting (Hermes-Midas systems). The most important component of any management decision support system in the energy sector is the fuel and energy sector model and its links to the rest of the economy. The article (Jebaraj \& Iniyan, 2006) reviews more than 250 energy models that are widely used in different countries for the purposes of analyzing and predicting energy development. Optimization models are analyzed, in particular: various types of

\footnotetext{
* Corresponding author: vagenina@rambler.ru
} 
models for optimizing the fuel and energy balance; step-by-step models for optimizing energy systems; models that minimize the energy intensity of GDP, taking into account various restrictions; models for planning energy supply and demand using a multi-criteria programming technique based on the traditional Leontiev input-output model. A special place in the modeling literature is given to computable general equilibrium (CGE) models (Dixon, Koopman \& Rimmer, 2013; Wickens, 2008). Due to their ability to model the system's response to external influences, these models are widely used for analyzing the consequences of management decisions (Adams \& Parmenter, 2013). In the field of energy, CGE models have emerged as useful empirical tools for assessing the scale of economic impacts of energy and environmental policies (Bohlmann et al., 2014; Farajzadeh \& Bakhshoodeh, 2015; Jorgenson et al., 2013; Winston, 2009) [5-6].

The author was most interested in Russian developments in the field of modeling and forecasting of energy in industry, since they take into account the features of national management institutions and statistical descriptions of modeling objects to a greater extent. Currently, the technology of energy modeling and forecasting developed at the Institute For energy research of the Russian Academy of Sciences (INEI RAS) (SCANER, 2011) is more proven. This method is successfully used for forecasting both Russian and global energy (evolution of global energy markets, 2015). The main feature of this technology is the formation of a consistent and mutually agreed system of forecasts of the country's economic development, consumption and production of basic fuels and energy, as well as financing of individual fuel and energy sectors. Iterative coordination in the forecast system is made through energy balances formed for the country as a whole and for individual regions, production characteristics and financial balances of fuel and energy industries, closed to intersectoral balances of the national economy [3-4].

\section{Research methodology}

In the study, within the framework of the integrated assessment methodology, the calculation of the integral coefficient of resource efficiency is proposed by the method of multidimensional classification (or multidimensional groupings) based on multidimensional averages. Since it is impossible to calculate the average value of the absolute values of different estimated parameters of an industry company, which are both quantitative and qualitative and expressed in different units of measurement, the total resource efficiency indicator is calculated from the relative values based on a multidimensional average: from the ratio of the individual values of the estimated parameters for each unit of the population to the average values of these parameters in the whole population:

$$
\bar{p}_{i}=\frac{\left(\sum_{j=1}^{n} p_{i j}+\sum_{j=1}^{n} p_{i j}^{\prime}\right)}{n},
$$

where $\bar{p}_{i}$ - is the overall resource efficiency indicator of the i-th industry company:

$p_{i j}, p_{i j}^{\prime}$ - the value of a single resource efficiency indicator for the $\mathrm{j}$-th estimated parameter, an increase in the value of which means an increase/decrease in the level of resource efficiency, respectively, for the i-th industry company;

$$
p_{i j}=\left(\frac{K_{i j}}{\bar{K}_{j}}\right) ; \quad p_{i j}^{\prime}=\left(\frac{\bar{K}_{j}}{K_{i j}}\right),
$$

$K_{i j}$ - individual value for the $\mathrm{j}$-th evaluation parameter of the $\mathrm{i}$-th industry company; 
$\bar{K}_{j}$ - the average value of the $\mathrm{j}$-th estimated parameter of the industry company as a whole in the aggregate;

$\omega$ - significance factor;

$\mathrm{i}$ - the number of the industry company included in the study population;

$\mathrm{j}$ - number of the estimated parameter;

$\mathrm{n}$ - number of estimated parameters.

It should be noted that the preferred characteristics of resource efficiency are significant to different degrees for the producer of different types of activities, therefore, the estimated parameters will affect the level of resource efficiency of the industry company to different degrees, so the calculation of the overall resource efficiency indicator should be carried out taking into account the significance coefficients:

$$
\bar{p}_{i}=\frac{\left(\sum_{j=1}^{n}\left(p_{i j} * \omega_{j}\right)+\sum_{j=1}^{n}\left(p_{i j}^{\prime} * \omega_{j}\right)\right)}{\sum_{j=1}^{n} \omega_{j}},
$$

Since the sum of the significance coefficients is always 1, the formula (3) will have the form:

$$
\bar{p}_{i}=\sum_{j=1}^{n}\left(p_{i j} * \omega_{j}\right)+\sum_{j=1}^{n}\left(p_{i j}^{\prime} * \omega_{j}\right)
$$

The weighting factors of the performance criteria allow us to assess their mutual importance for the industry company in question.

Based on the calculation of the overall indicator, the level of resource efficiency of an industry company is estimated as follows:

- if $\bar{p}_{i}$ more than 1.0, then the industry company is resource-efficient in the market under study

- if $\bar{p}_{i}$ less than 1.0, then the industry company is not resource-efficient.

During the survey, experts were asked to evaluate the feasibility of applying each of the presented gradations to establish groups of industry companies by the level of resource efficiency (table 1).

Table 1. Composition of the expert group for setting ranges of resource efficiency indicators of industry companies.

\begin{tabular}{|c|c|}
\hline Name of the organization & $\begin{array}{c}\text { Number of } \\
\text { experts, person }\end{array}$ \\
\hline $\begin{array}{c}\text { Territorial body of the Federal State Statistics Service for the Tyumen } \\
\text { Region }\end{array}$ & 3 \\
\hline Gazprom Dobycha Nadym LLC» & 3 \\
\hline Gazprom Pererabotka Surgut, LLC» & 3 \\
\hline Gazprom Transgaz Surgut, LLC» & 3 \\
\hline LLC Sibur Tobolsk & 3 \\
\hline JSC Tarkosaleneftegaz PJSC Novatek & 3 \\
\hline Purovsky ZPK PJSC Novatek & 2 \\
\hline Total & 20 \\
\hline
\end{tabular}

Based on the results of processing the obtained material, the most appropriate gradation of the values of the integral and partial indicators of the resource efficiency of the industry company is determined. The assessment of the gradation of the values of the resource efficiency indicators of an industry company by experts is presented in Table 2 . 
Table 2. Assessment of the gradation of the values of resource efficiency indicators of an industry company by experts.

\begin{tabular}{|c|c|c|c|c|c|c|c|c|c|c|c|}
\hline \multirow{2}{*}{$\begin{array}{l}\text { Name of the } \\
\text { gradation }\end{array}$} & \multicolumn{10}{|c|}{ Experts } & \multirow[t]{2}{*}{ Significance factor } \\
\hline & 1 & 2 & 3 & 4 & 5 & 6 & $\ldots$ & 18 & 19 & 20 & \\
\hline Three-level & 3 & 3 & 3 & 3 & 3 & 3 & $\ldots$ & 3 & 3 & 3 & 0,250 \\
\hline Four-level & 1 & 2 & 2 & 2 & 2 & 1 & $\ldots$ & 2 & 2 & 2 & 0,354 \\
\hline Five-level & 2 & 1 & 1 & 1 & 1 & 2 & $\ldots$ & 1 & 1 & 1 & 0,396 \\
\hline \multicolumn{6}{|c|}{$\mathrm{S}=632$} & & $\overline{9,813}$ & & & otal & 1,000 \\
\hline
\end{tabular}

The resulting concordance coefficient differs significantly from zero - 0.813 fractions of units. Consequently, there is a fairly close consistency of expert opinions in the application of the 5-level gradation of the values of the integral and partial indicators of resource efficiency, as well as the range of their values presented in Table 3.

Table 3. Gradation of indicator values.

\begin{tabular}{|c|c|c|c|c|c|c|}
\hline \multirow{3}{*}{$\begin{array}{l}\text { Industry companies } \\
\text { by resource efficiency } \\
\text { level }\end{array}$} & \multicolumn{6}{|c|}{ Ranges of values } \\
\hline & \multirow{2}{*}{$\begin{array}{l}\text { integral } \\
\text { indicator }\end{array}$} & \multicolumn{5}{|c|}{ private indicators } \\
\hline & & $\begin{array}{l}1,0 ; \\
0,8] \\
\end{array}$ & $\begin{array}{c}0,79 \\
0,6]\end{array}$ & $\begin{array}{c}0,59 \\
0,4] \\
\end{array}$ & $\begin{array}{c}0,39 \\
0,2] \\
\end{array}$ & $\begin{array}{c}0,19 \\
0,0]\end{array}$ \\
\hline $\begin{array}{c}\text { Companies with a high } \\
\text { level of resource } \\
\text { efficiency }\end{array}$ & $\begin{array}{l}{[1,0 ; 0,8]} \\
2,0 ; 2,05\end{array}$ & ++ & & & & \\
\hline $\begin{array}{l}\text { Companies with } \\
\text { above-average } \\
\text { resource efficiency }\end{array}$ & $\begin{array}{c}{[0,79 ; 0,6]} \\
2,04\end{array}$ & \pm & + & & & \\
\hline $\begin{array}{l}\text { Companies with an } \\
\text { average level of } \\
\text { resource efficiency }\end{array}$ & {$[0,59 ; 0,4]$} & & \pm & + & \pm & \\
\hline $\begin{array}{l}\text { Companies with } \\
\text { below-average } \\
\text { resource efficiency }\end{array}$ & {$[0,39 ; 0,2]$} & & & & + & \pm \\
\hline $\begin{array}{l}\text { Companies with low } \\
\text { resource efficiency }\end{array}$ & {$[0,19 ; 0,0]$} & & & & & ++ \\
\hline
\end{tabular}

Note: "++ "- all private performance indicators are in the selected range of values; " + "most of the private indicators are in the selected range of values; " $\pm "$ - individual private indicators may be in the selected range of values.

\section{Results of the study}

In accordance with the proposed gradation method, it is possible to judge the level of resource efficiency of an industry company or a segment of the gas industry, depending on the obtained value of the integral indicator [7-8,12]. The set of indicators of resource efficiency of industrial companies developed by the authors is shown in Fig.1.

Such a set of selected criteria for evaluating the resource efficiency of gas companies allows:

- identify the segments of gas production, processing and transportation and assess their contribution to the overall resource efficiency of the gas industry;

- evaluate the resource-efficient development aspects of each segment in the gas industry; - identify areas and develop measures to improve the resource efficiency of gas companies and the economic security of the gas industry as a whole. 


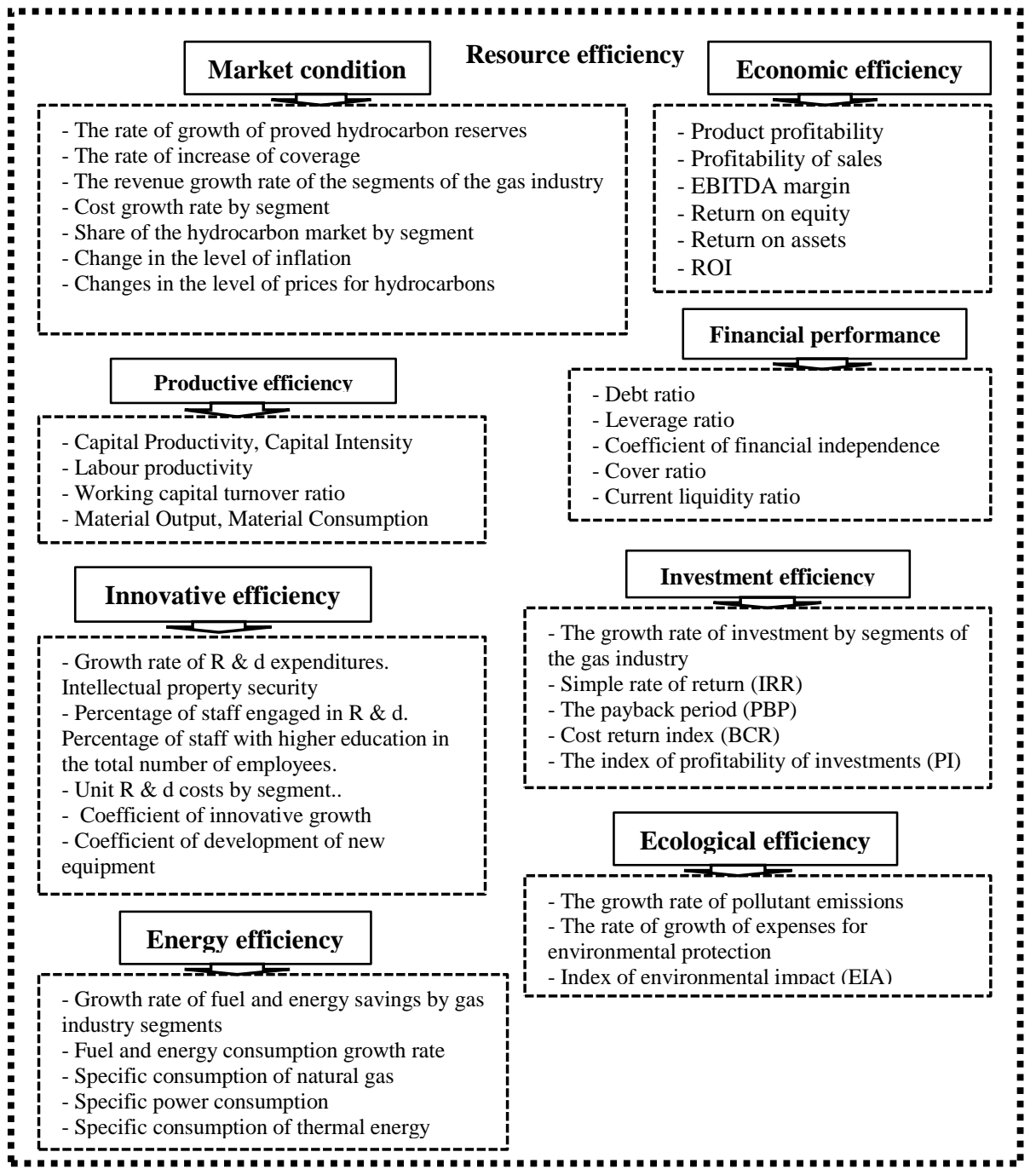

Fig.1. A set of indicators of resource efficiency of gas companies.

Based on the proposed methodology for a comprehensive assessment of resource efficiency indicators, an analysis of the current state of activity of the segments "gas production" - PJSC "Novatek", "gas processing" - JSC "Sibur" and "gas pipeline transport" PJSC "Gazprom" for 2016-2020 was carried out [9-11].

As a result of the analysis for 2016-2020 of the production and economic activities of gas companies by industry segments, the authors proved that there is a steady decline in economic and investment efficiency in pipeline transport. However, production, energy and environmental activities are at a fairly high level. In the gas production and processing segments, on the contrary, there is a high efficiency of economic, financial and investment activities, while the efficiency of production, energy and environmental activities leaves much to be desired.

The calculation of the integral coefficient in the forecast period up to 2025 made it possible to determine the level of resource efficiency of an industry company or a segment of the gas industry, depending on the obtained value of the indicator (Fig. 2). Thus, at the first level are the efficiency indicators in the production and processing segments and have 
the highest values compared to gas transportation. At the second level are the segments of gas processing and transportation. A significant number of third-tier companies were engaged in gas production and transportation compared to the gas processing segment.

At the beginning of the analyzed period (2016), a high level of resource efficiency was observed in gas transportation and the lowest in gas processing. In gas production for the entire analyzed period, the level of resource efficiency is relatively stable, but in the forecast period (2025), it is expected to grow by $23.6 \%$. If the level of resource efficiency for the gas processing activities of Sibur does not change for the period of the analysis of 2016-2020 and the forecast of 2025, then for the gas pipeline transport activities, the decrease in the integral indicator from 3.05 in 2016 to 1.95 by 2020 was $56.4 \%$.

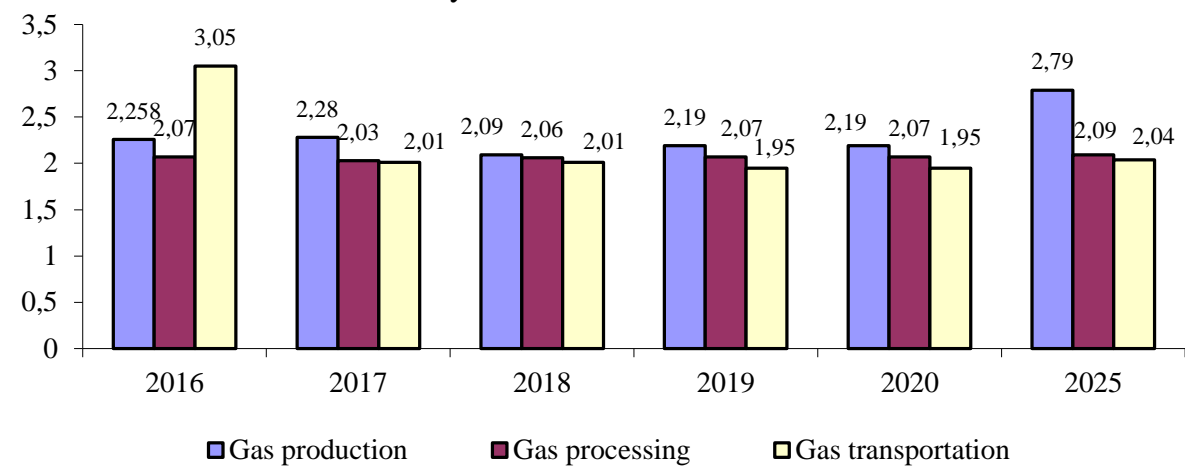

Fig. 2. Dynamics of the integral coefficient of industry companies.

\section{Discussion of the results}

The multi-variant nature of the conditions for resource-efficient development of the socioeconomic system implies that management decisions cannot in principle be one-time and directive, but should be regularly reviewed in relation to changing conditions using constantly operating management decision support systems that take into account the real properties of the gas industry and the segments of gas production, processing and transport. Since management decisions in the gas industry and the segments of gas production, processing and transport may contradict each other, it is advisable to search for the best ratios between the indicators of general economic and resource efficiency within the framework of a single multi-criteria optimization task, where, along with general economic goals, the guidelines for resource-efficient development are set in the form of targets for the selected system of resource indicators. The choice of the composition of resource indicators should answer the question of which development is considered as resource-efficient. The weight coefficients of resource indicators allow you to place "resource-efficiency accents", correcting the solution of the general problem of finding a scenario for resource-efficient development in the right direction. The authors, using regulatory documents, developed a methodology for a comprehensive assessment of resource efficiency, which characterizes the development of the gas industry, gas production, processing, and transportation segments, and large gas companies in terms of resource intensity, resource efficiency, resource conservation, and resource safety. The advantage of the proposed system of resource indicators is its reliability and balance. 


\section{Conclusion}

The methods and tools presented in the study for forecasting and strategic planning of resource-efficient development of the gas industry, gas production, processing, and transportation segments, and large gas companies are implemented in the form of a predictive and analytical system aimed at supporting management decisions to improve resource efficiency and economic security. Participation in management decision-making procedures required full compliance with the conceptual and information structure of the model tools used in official statistics and maximum use of production data in calculations. The model tools were tested on the statistical and reporting materials of NOVATEK, SIBUR, and GAZPROM [9-11].

Testing of the methodology for a comprehensive assessment of resource efficiency in the context of the implementation of industry companies ' own growth strategies showed that the transformation stage is characterized by the presence of multi-oriented prospects for the development of the gas industry, the target orientation of the country's energy strategy and the level of resource efficiency are reduced, and also does not correspond to the concept of sustainable development.

\section{Acknowledgment}

The research was funded by RFBR and Tyumen Region, project number 20-47-720001.

\section{References}

1. A. Makarov and L. M. Grigoriev, T. A. Microway, Forecast of development of world energy and Russia-2016. https://www.eriras.ru/data/772/rus

2. Energy Bulletin "Development of competition in gas markets". Analytical center under the Government of the Russian Federation, 37 (2016)

3. Energy Bulletin "energy Efficiency to prevent climate change". Analytical center under the Government of the Russian Federation, 57 (2018)

4. Energy Bulletin "New world energy forecasts and Russia's place in it". Analytical center under the Government of the Russian Federation, 54 (2017)

5. Energy Bulletin "Russian gas in the East Europe: new conditions". Analytical center under the Government of the Russian Federation, 46 (2017)

6. Energy strategy of Russia for the period up to 2035. http://minenergo.gov.ru/node/1913

7. L.V. Vagenina, Project Management of Strategy for Energy Efficiency and Energy Conservation in the Gas Sector of the Economy (Studies on Russian Economic Development, 2015)

8. L.V. Vazhenina. Improving resource efficiency in the russian gas industry: monograph (Tyumen, TIU, 2017)

9. Report of PJSC Gazprom for 2015-2020. http://www.gazprom.ru

10. SIBUR annual review 2015-2020. http:// www.sibur.ru

11. The annual report of NOVATEK for 2015-2020. http:// www.novatek.ru

12. V. Tsybatov, L. Vazhenina, Methodical Approaches To Analysis And Forecasting Of Development Fuel And Energy Complex And Gas Industry In The Region (2014) 